NASA/TM-2002-211804

\title{
Efficient Design in a DC to DC Converter Unit
}

Joel E. Bruemmer and Fitch R. Williams

The Boeing Company, Canoga Park, California

Gregory V. Schmitz

Glenn Research Center, Cleveland, Ohio 
Since its founding, NASA has been dedicated to the advancement of aeronautics and space science. The NASA Scientific and Technical Information (STI) Program Office plays a key part in helping NASA maintain this important role.

The NASA STI Program Office is operated by Langley Research Center, the Lead Center for NASA's scientific and technical information. The NASA STI Program Office provides access to the NASA STI Database, the largest collection of aeronautical and space science STI in the world. The Program Office is also NASA's institutional mechanism for disseminating the results of its research and development activities. These results are published by NASA in the NASA STI Report Series, which includes the following report types:

- $\quad$ TECHNICAL PUBLICATION. Reports of completed research or a major significant phase of research that present the results of NASA programs and include extensive data or theoretical analysis. Includes compilations of significant scientific and technical data and information deemed to be of continuing reference value. NASA's counterpart of peerreviewed formal professional papers but has less stringent limitations on manuscript length and extent of graphic presentations.

- TECHNICAL MEMORANDUM. Scientific and technical findings that are preliminary or of specialized interest, e.g., quick release reports, working papers, and bibliographies that contain minimal annotation. Does not contain extensive analysis.

- CONTRACTOR REPORT. Scientific and technical findings by NASA-sponsored contractors and grantees.
- CONFERENCE PUBLICATION. Collected papers from scientific and technical conferences, symposia, seminars, or other meetings sponsored or cosponsored by NASA.

- SPECIAL PUBLICATION. Scientific, technical, or historical information from NASA programs, projects, and missions, often concerned with subjects having substantial public interest.

- TECHNICAL TRANSLATION. Englishlanguage translations of foreign scientific and technical material pertinent to NASA's mission.

Specialized services that complement the STI Program Office's diverse offerings include creating custom thesauri, building customized databases, organizing and publishing research results ... even providing videos.

For more information about the NASA STI Program Office, see the following:

- Access the NASA STI Program Home Page at http://www.sti.nasa.gov

- E-mail your question via the Internet to help@sti.nasa.gov

- Fax your question to the NASA Access Help Desk at 301-621-0134

- Telephone the NASA Access Help Desk at 301-621-0390

- Write to:

NASA Access Help Desk

NASA Center for AeroSpace Information 7121 Standard Drive

Hanover, MD 21076 
NASA/TM-2002-211804

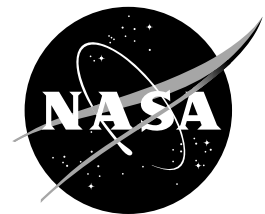

\section{Efficient Design in a DC to DC Converter Unit}

Joel E. Bruemmer and Fitch R. Williams

The Boeing Company, Canoga Park, California

Gregory V. Schmitz

Glenn Research Center, Cleveland, Ohio

Prepared for the

37th Intersociety Energy Conversion Engineering Conference sponsored by the Institute of Electrical and Electronics Engineers, Electron Devices Society

Washington, DC, July 28-August 2, 2002

National Aeronautics and Space Administration

Glenn Research Center 
Available from

NASA Center for Aerospace Information 7121 Standard Drive

Hanover, MD 21076
National Technical Information Service 5285 Port Royal Road Springfield, VA 22100

Available electronically at http://gltrs.grc.nasa.gov 
IECEC 200220032

\title{
EFFICIENT DESIGN IN A DC TO DC CONVERTER UNIT
}

\author{
Joel E. Bruemmer and Fitch R. Williams \\ The Boeing Company \\ 6633 Canoga Avenue \\ Canoga Park, CA 91303 \\ Gregory V. Schmitz \\ National Aeronautics and Space Administration \\ Glenn Research Center \\ 21000 Brookpark Road \\ Cleveland, $\mathrm{OH} 44135$
}

\begin{abstract}
Space Flight hardware requires high power conversion efficiencies due to limited power availability and weight penalties of cooling systems. The International Space Station (ISS) Electric Power System (EPS) DC- DC Converter Unit (DDCU) power converter is no exception. This paper explores the design methods and tradeoffs that were utilized to accomplish high efficiency in the DDCU. An isolating DC to DC converter was selected for the ISS power system because of requirements for separate primary and secondary grounds and for a wellregulated secondary output voltage derived from a widely varying input voltage. A flybackcurrent-fed push-pull topology, or improved Weinberg circuit, was chosen for this converter because of its potential for high efficiency and reliability. To enhance efficiency, a nondissipative snubber circuit for the very-low-Rdson Field Effect Transistors (FET)s was utilized, redistributing the energy that could be wasted during the switching cycle of the power FETs. A unique, low-impedance connection system was utilized to improve contact resistance over a bolted connection. For improved consistency in performance and to lower internal wiring inductance and losses, a planar bus system is employed. All of these choices contributed to the design of a $6.25 \mathrm{KW}$ regulated dc to dc converter that is $95 \%$ efficient.

The methodology used in the design of this DC to DC Converter Unit may be directly applicable to other systems that require $a$
\end{abstract}

conservative approach to efficient power conversion and distribution.

\section{INTRODUCTION}

Power converters used for spacecraft have more unique requirements than their terrestrial counterparts. Due to physical constraints, solar arrays can produce only a limited quantity of power. Since this energy is restricted, efficiency plays a very important part in the choice of topology for the design of a spacecraft power converter. In addition to limited power availability, the heat generated by the conversion process must be radiated into space. The weight burden for these radiators may be substantial. These were two of the many unique problems facing the design team on the International Space Station when developing the DC to DC Converter Unit.

\section{WHY A DDCU?}

The International Space Station is modularized. Each section of the station is assembled and tested on earth and then attached to the growing structure on orbit. It is analogous to building a house a room at a time with all the wiring, mechanics, and support structures in place before adding it to the main house. The DC distribution system for each of these modules requires isolation so that individual grounds will not interact with each other. The solution to this electrical problem was a power distribution system that would isolate each of these grounds and also 
distribute power from the arrays to each interconnected module.

The Sequential Shunt Unit coarsely regulates the voltage supplied by the arrays to a preset value between 115 to 173 volts. The many uses of this DC power supplied by the arrays vary from simple lighting to sophisticated S-band transmitters and receivers. Each of these loads requires an input voltage that is free from noise spikes that may be generated by the primary switching and a tightly regulated input which will simplify its internal power conversion needs. Therefore, what was needed was a unit that provided DC isolation and regulation.

\section{WHAT IS A DDCU?}

From a black box standpoint, the DDCU must regulate the widely varying voltage from the arrays (115 to 173 volts) to a constant 124.5 \pm 1.5 volts. Loading may be very light $(<1 \mathrm{Amp})$, very heavy ( $>50 \mathrm{Amps}$ ), and reach overload conditions (= 80 Amps). The output must be short circuit proof. A fault in one area of the station must not render the whole power system inoperative. The DDCU is required to communicate via a Mil-Std-1553-type bus where all the modules in the power system share their status over telemetry channels. The input current and voltage, and output current and voltage are required to be internally monitored and reported over this bus. In addition, the output of the DDCU needs to turn off if the input voltage exceeds the 173-volt maximum, if the output current exceeds the 52 Amp maximum by $125 \%$ and $150 \%$, or if the input current exceeds a predefined safe limit. This Input Current Shutdown is a safety measure should something go wrong with the DDCU internally.

The DDCU is manufactured in three versions: an external type (DDCU-E) used on the Integrated Equipment Assemblies (IEA) for distribution of power to each of the four main structures; an internal type (DDCU-I), used inside pressurized elements for distribution of power to experiments and other internal loads; a passively cooled type (DDCU-HP), used only on the $\mathrm{Z} 1$ truss segment and is a heat-pipe-cooled variation of the external type. The internal type only, is capable of being paralleled with another DDCU-I so that the power delivered can be doubled while the input power is distributed between the arrays (the input to each of the paralleled DDCU-Is is from a different source).

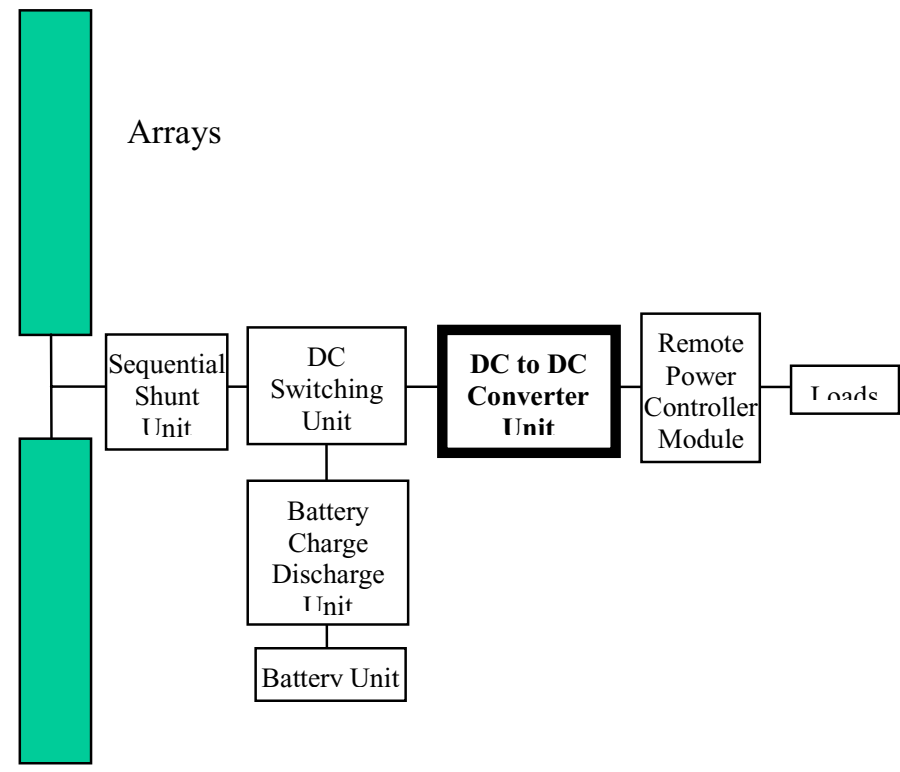

Figure 1. Power System Block Diagram of the Integrated Equipment Assembly (IEA)

\section{CHOICE OF TOPOLOGY}

Efficiency was the major driver for the topology chosen. The primary function of generating power is to deliver it to the loads. On orbit, there is a limited amount of power available from the arrays and batteries. Waste heat is also a major consideration. Heat is rejected through an ammonia-cooled baseplate and radiator system facing deep space. An estimated $5 \%$ efficiency decrease in the DDCU would increase the cooling system weight by $100 \mathrm{lb}$. on one Integrated Equipment Assembly (IEA).

For these reasons, a flyback-current-fed push-pull (Weinberg) topology was chosen. The advantages are high power conversion ratio (efficiency), continuous conduction to the output node, lack of flux imbalance in the power transformer, and no possibility of damaging the switching elements due to switching overlap.

One shortcoming of this topology is that the power- switching elements must be rated at a higher voltage than those of other circuit types. The minimum voltage impressed on the switching elements is twice the input voltage due to the push-pull configuration of the power transformer. Added to this is the voltage spike generated each switching cycle by the flyback inductor. Finally the combined leakage inductance of both magnetic units provides another voltage overshoot that further increases the instantaneous voltage seen by the switching elements. 
The choice of power switching element was very important to efficient design. Highcurrent bipolar devices require substantial basedrive power, which hurts efficiency unless regenerative drives are used. High gain bipolar devices, such as Darlingtons, have a high saturation voltage drop. Insulated-gate-bipolartransistors (IGBTs) have a similar problem with conduction losses. Thyristors are not noted for radiation hardness and are subject to noise/rate triggering as well as junction voltage drop losses. Power Field Effect Transistors (FET) were the optimum choice for this application due to their potential for radiation hardness and very low 'on-resistance.' However, FETs that were capable of the required power (low Rds_on) were not available. This void necessitated the development a new breed of power FET capable of reliably switching $100 \mathrm{Amps}$ and rated at 500 volts, minimum.

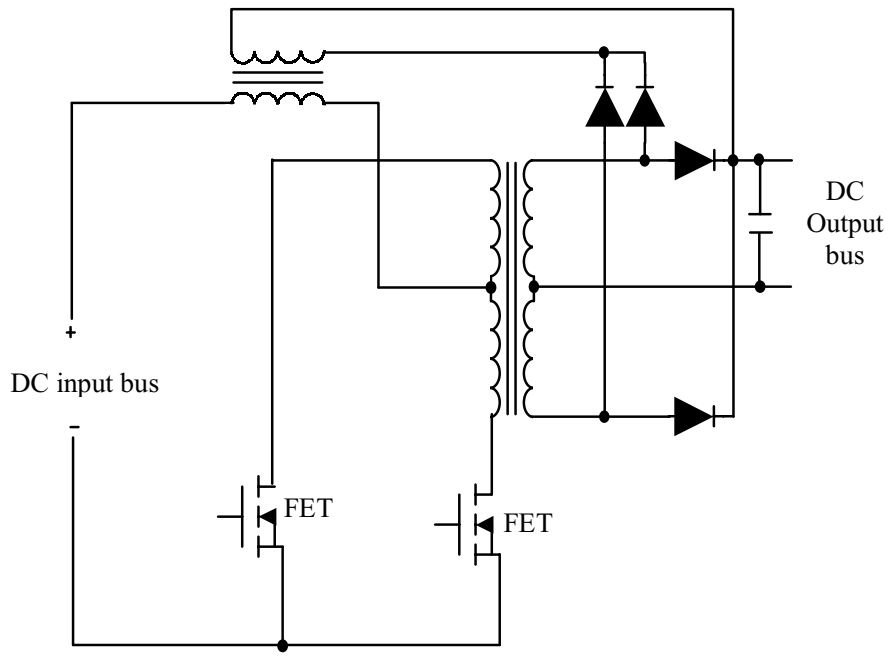

Figure 2. Improved Weinberg Topology

After a substantial development time, a FET that could switch the required power was produced and successfully demonstrated in a prototype DDCU. During this time, the basic design of the DDCU was formulated and the necessary building blocks were assembled to implement a reliable product.

\section{NON-DISSIPATIVE SNUBBER}

In this Weinberg topology, the power switching transistors are in series with the power transformer primary. During the turn-off of the switching element, the leakage inductance of the power transformer generates a voltage in excess of the expected "twice input" voltage overshoot. If unmanaged, this excursion may exceed the voltage rating of the power FET. Normally, an RC snubber is used to limit this overshoot. However, this is wasted energy. A "non-dissipative snubber" provides a solution and increases the overall converter efficiency. Just as in a conventional RC snubber, the nondissipative snubber uses a capacitor to slow up the switching element rise time. However, it does not get rid of the resulting charge on the capacitor by discharging it through a resistor. Instead, the energy stored in the capacitor is transferred to an inductor that is later forced to return its stored energy back into the DC input bus. The use of steering diodes helps to accomplish this recovery.

The details can be seen in Figure 3. As the FET turns off, its drain voltage starts rising; the upper diode between the DC input bus and capacitor turns on, and the capacitor slows the voltage rise time. One end of the capacitor is driven up to approximately twice the input voltage and the other end is clamped to the DC input bus through the diode. When the FET turns on, the charged capacitor is switched across the inductor with the lower diode in series. This results in an oscillatory current ring with a frequency $F_{r}=1 / 2 \pi(L C)^{1 / 2}$. At the end of this half period, the stored energy in the capacitor has been changed to stored energy in the inductor. During the next half period, the voltage at the top of the inductor rings positive enough for the upper diode to conduct and the energy stored in the inductor flows back to the DC input bus.

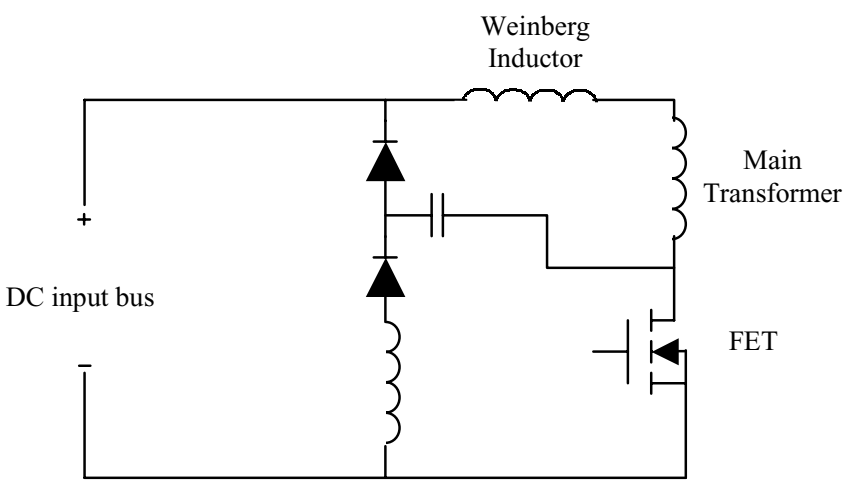

Figure 3. Non-dissipative Snubber

Unfortunately, this circuit has one drawback: the time required to fully discharge the inductor may be interrupted by a short 'ontime' of the FET. This results in a shortened discharge pulse and the consequential leakage 
inductance overshoot may exceed the rating of the FET. Since the DDCU has a large variation in output load, this scenario may occur at light loads and high line input voltage. A compromise was struck between the non-dissipative and the standard RC snubbers. A light RC snubber was added to just keep the leakage inductance voltage overshoot under the rating of the FET at no load. This prevented the FET from reaching the avalanche level and also returned as much energy as possible to the input from the nondissipative snubber.

\section{HIGH-CURRENT CONTACTS}

Electromagnetic Compatibility (EMC) requirements for the DDCU necessitated a design in which the switching frequency and harmonic noise generated by the FET could not escape through the input or output buses. To this end, the power section and input and output filters were compartmentalized. Power connections from one compartment to another were accomplished via feed-thru filters, an isolated connection point with a capacitor connected to chassis.

In the early design of the DDCU, these feed-thru filters were off-the-shelf devices in which the connection point was a threaded stud, secured via a crimp-on ring lug terminal. The power loss of this type of terminal proved to be unacceptable. For example, if only one contact had a 1 milli-Ohm resistance, at 90 Amps the loss would be 8.1 Watts. These connections were at best a point contact that created an unacceptable power loss. Although a reliable connection could be made with gold contacts and guaranteed flatness, the threaded stud method did not lend itself to flatness or any acceptable design alternative. Another way had to be found.

Consulting industry, a louvered, highcurrent contact was found which was used on diesel locomotives and for submarine ship to shore power. This system was adapted to and then checked out in the DDCU. These contacts proved to be very successful and were employed for all high current connections within the DDCU. This system provides an additional advantage of mechanical design flexibility with an easy, push-on circuit connection. These contacts also helped to solve a rather tricky stability problem that will be discussed next.

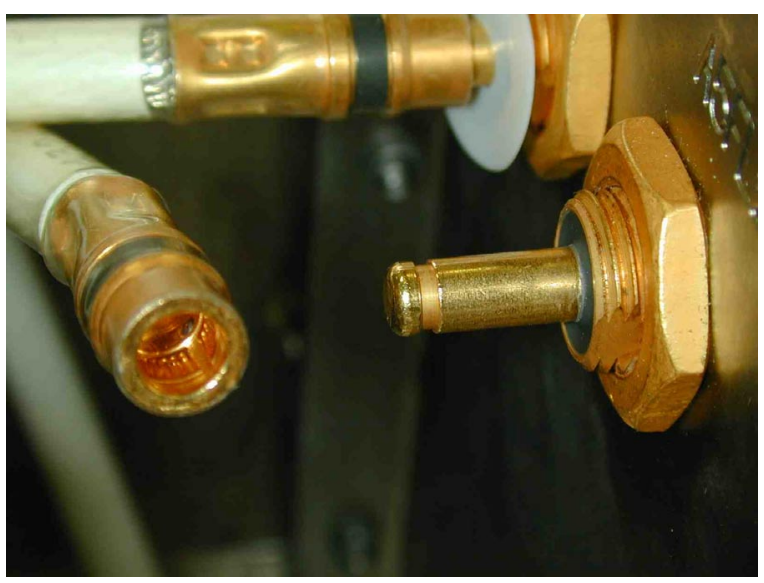

Figure 3. High Current Louvered Contact

\section{PLANAR BUS}

In the DDCU, the output voltage is sensed via a resistor divider at the output filter and summed within the pulse width modulator (PWM) circuit located on the Feedback Assembly. The PWM output dictates the 'ontime' for each FET. Before being applied to the PWM, the voltage sense signal is conditioned by the compensation amplifier. The values of the components comprising this amplifier circuit are critical to the stability of the DDCU. If the stability were compromised, the control circuit might oscillate, rendering the DDCU inoperative and possibly damaging its loads.

During the early development of the DDCU, the compensation amplifier component values were constantly changing. The values necessary for stability varied from unit to unit. Small changes in wiring within the DDCU power section would require additional changes to these component values to eliminate oscillations. The cause of the instability was traced to inductive losses due to the type of circular wiring being used to connect the high power components (FET, transformer, snubber, Weinberg inductor, etc.), and the variation of these losses from unit to unit. A solution was realized by the combination of the high-current, push-on contacts and insulated, flat copper conductors, i.e., the Planar Bus.

Planar buses are preformed, flat copper sheets, coated and separated by an insulator and fashioned so that the effects of equal and opposing currents in the power flow will be canceled out. 


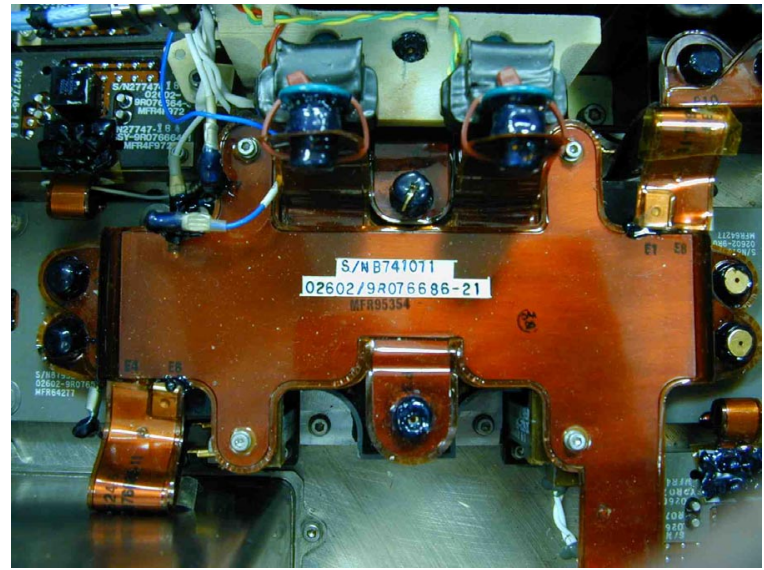

Figure 4. DDCU Primary Planar Bus

This power component interconnect scheme provided close coupling of opposing currents and thereby reduced magnetic field and 'noise' generation. The net effect was to reduce the length of high current paths and their related inductances. This, in turn, provided the necessary wiring consistency and allowed the compensation amplifier component values to be optimized for stability.

An additional benefit was to enable more efficient power component location and simplified assembly due to these preformed power buses.

\section{CONCLUSION}

Power converters for spacecraft generally have very unique requirements. Due to cooling system limitations and power availability, efficiency plays a significant role in converter selection and design. These configuration choices utilized in the ISS DDCU can be directly applied to commercial and industrial designs where efficiency may not be quite as important, but conservation of energy as a whole would benefit.

The power system for the International Space Station required a converter that provided electrical ground isolation and load simplification. The DDCU was designed to fulfill the requirements of high efficiency and isolation.

Design criteria indicated that the DDCU efficiency should be at least $90 \%$ from medium to full load. Meeting these requirements was aided through the use of Weinberg topology, a non-dissipative snubber, high-current contacts and planar bus technology. This allowed for efficiencies greater than $95 \%$ and a design that reduced the overall cooling requirements.

Innovations and technology developments from the U.S. space program are regularly applied to industrial and commercial products. The efficiency enhancements discussed herein can similarly be adapted by the private sector for improvements in its power conversion products. 
Public reporting burden for this collection of information is estimated to average 1 hour per response, including the time for reviewing instructions, searching existing data sources, gathering and maintaining the data needed, and completing and reviewing the collection of information. Send comments regarding this burden estimate or any other aspect of this collection of information, including suggestions for reducing this burden, to Washington Headquarters Services, Directorate for Information Operations and Reports, 1215 Jefferson Davis Highway, Suite 1204, Arlington, VA 22202-4302, and to the Office of Management and Budget, Paperwork Reduction Project (0704-0188), Washington, DC 20503.

\begin{tabular}{|l|l|l|}
\hline 1. AGENCY USE ONLY (Leave blank) & $\begin{array}{c}\text { 2. REPORT DATE } \\
\text { August } 2002\end{array}$ & $\begin{array}{r}\text { 3. REPORT TYPE AND DATES COVERED } \\
\text { Technical Memorandum }\end{array}$ \\
\hline
\end{tabular}

4. TITLE AND SUBTITLE

5. FUNDING NUMBERS

Efficient Design in a DC to DC Converter Unit

6. AUTHOR(S)

WU-478-29-10-00

Joel E. Bruemmer, Fitch R. Williams, and Gregory V. Schmitz

7. PERFORMING ORGANIZATION NAME(S) AND ADDRESS(ES)

National Aeronautics and Space Administration

John H. Glenn Research Center at Lewis Field

Cleveland, Ohio 44135-3191

8. PERFORMING ORGANIZATION

REPORT NUMBER

E-13499

9. SPONSORING/MONITORING AGENCY NAME(S) AND ADDRESS(ES)

National Aeronautics and Space Administration

Washington, DC 20546-0001

10. SPONSORING/MONITORING

AGENCY REPORT NUMBER

NASA TM-2002-211804

IECEC-2002-20032

\section{SUPPLEMENTARY NOTES}

Prepared for the 37th Intersociety Energy Conversion Engineering Conference sponsored by the Institute of Electrical and Electronics Engineers, Electron Devices Society, Washington, DC, July 28-August 2, 2002. Joel E. Bruemmer and Fitch R. Williams, The Boeing Company, 6633 Canoga Avenue, Canoga Park, California 91303; Gregory V. Schmitz, NASA Glenn Research Center. Responsible person, Gregory V. Schmitz, organization code 6920, 216-433-8327.

12a. DISTRIBUTION/AVAILABILITY STATEMENT

12b. DISTRIBUTION CODE

Unclassified - Unlimited

Subject Category: 20

Distribution: Nonstandard

Available electronically at http://gltrs.grc.nasa.gov

This publication is available from the NASA Center for AeroSpace Information, 301-621-0390.

13. ABSTRACT (Maximum 200 words)

Space Flight hardware requires high power conversion efficiencies due to limited power availability and weight penalties of cooling systems. The International Space Station (ISS) Electric Power System (EPS) DC- DC Converter Unit (DDCU) power converter is no exception. This paper explores the design methods and tradeoffs that were utilized to accomplish high efficiency in the DDCU. An isolating DC to DC converter was selected for the ISS power system because of requirements for separate primary and secondary grounds and for a well-regulated secondary output voltage derived from a widely varying input voltage. A flyback-current-fed push-pull topology or improved Weinberg circuit was chosen for this converter because of its potential for high efficiency and reliability. To enhance efficiency, a non-dissipative snubber circuit for the very-low-Rds-on Field Effect Transistors (FETs) was utilized, redistributing the energy that could be wasted during the switching cycle of the power FETs. A unique, low-impedance connection system was utilized to improve contact resistance over a bolted connection. For improved consistency in performance and to lower internal wiring inductance and losses a planar bus system is employed. All of these choices contributed to the design of a $6.25 \mathrm{KW}$ regulated dc to dc converter that is 95 percent efficient. The methodology used in the design of this DC to DC Converter Unit may be directly applicable to other systems that require a conservative approach to efficient power conversion and distribution.

\begin{tabular}{|c|c|c|c|}
\hline \multirow{2}{*}{\multicolumn{3}{|c|}{ Spacecraft power; Power converter }} & $\begin{array}{c}\text { 15. NUMBER OF PAGES } \\
11\end{array}$ \\
\hline & & & 16. PRICE CODE \\
\hline $\begin{array}{l}\text { 17. SECURITY CLASSIFICATION } \\
\text { OF REPORT } \\
\text { Unclassified }\end{array}$ & $\begin{array}{l}\text { 18. SECURITY CLASSIFICATION } \\
\text { OF THIS PAGE } \\
\text { Unclassified }\end{array}$ & $\begin{array}{l}\text { 19. SECURITY CLASSIFICATION } \\
\text { OF ABSTRACT } \\
\text { Unclassified }\end{array}$ & 20. LIMITATION OF ABSTRACT \\
\hline
\end{tabular}

NSN 7540-01-280-5500

Standard Form 298 (Rev. 2-89)

Prescribed by ANSI Std. Z39-18 298-102 

